\title{
Consequential ' $O$-clauses in Tongan and Licensing of Null Anaphors
}

\author{
Yuko Otsuka \\ University of Hawai 'i
}

\section{Introduction}

Tongan (Polynesian) manifests ergativity not only in case morphology, but also with respect to certain syntactic operations: e.g., only ABS-marked NPs can undergo relativization by the gap strategy and deletion under pea-coordination. As is well known, not all languages with ergative case morphology show syntactic ergativity. For this reason, syntactic ergativity has been regarded as a phenomenon independent of morphological ergativity (Bittner and Hale 1996a, b, Dixon 1979,1994$){ }^{1}$ Contrary to such a view, I have proposed elsewhere that syntactic ergativity should be understood as a direct consequence of morphological ergativity, showing that in Tongan an ergative pattern arises because the relevant syntactic operation is subject to case feature matching requirement (Otsuka 2002, 2003).

There is, however, one instance of syntactic ergativity in Tongan that seems to contradict this claim. In ' $o$-constructions, what follows ' $O$ may contain a null argument. The null argument itself may be a subject (ABS or ERG) or a direct object. On the other hand, its antecedent must be an ABS-marked NP. Apparently, case matching requirement cannot account for this phenomenon, for the null argument and its antecedent may bear different cases. I argue, however, that this condition can also be viewed simply as a by-product of morphological ergativity. Specifically, I propose that the empty category in ' $o$-clauses is a null anaphor $\left(\right.$ pro $_{\mathrm{SE}}$ ) and that the binding condition for pro $\mathrm{SE}_{\mathrm{SE}}$ has to do with case.

In what follows, we will first put forward the claim that syntactic ergativity results from morphological ergativity by examining relativization and pea-coordination in Tongan (Section 2). In Sections 3 and 4, we compare ' $o$ constructions with pea-constructions to conclude a) that unlike pea, 'o should be regarded as a complementizer rather than a conjunction; and b) that the gap in ' $o$ clauses is not an outcome of deletion, but a null anaphor. We will then discuss a Minimalist approach to binding proposed by Reuland (2001) and see how it accounts for the distribution and behavior of pro $_{\mathrm{SE}}$ in Tongan. Some implications of the current proposal are discussed in Section 6, with section 7 in conclusion.

\section{Syntactic ergativity in Tongan: Relativization and pea-coordination}

Tongan has two relativization strategies: the gap strategy and the pronoun strategy. The former leaves a gap in the relative clause, while the latter requires a resumptive pronoun inside the relative clause. When the relativized argument is associated with an ABS-position, the gap strategy must be used. When the relativized argument is associated with an ERG-position, a resumptive pronoun is required. See (1) below., ${ }^{2,3}$ 
(1) a. e fefine [na'e tangi $t$ ]

DEF woman PST cry

'the woman (who) cried'

b. e fefine [na'e fili 'e Sione]

DEF woman PST choose ERG Sione

'the woman (who) Sione chose'

c. *e fefine [na'e fili 'a Sione]

DEF woman PST choose ABS Sione

'the woman (who) chose Sione'

d. e fefine [na'a ne fili 'a Sione]

DEF woman PST 3.S choose ABS Sione

'the woman (who) she chose Sione'

Otsuka (2002) proposes that the gap in a relative clause must be licensed by C through feature-matching. The operation in question is twofold. First, following Suñer (1998), C of a relative clause is assumed to have a [+pron(ominal)] feature. When this feature is strong, it forces movement of a pronominal element (i.e., relative pronoun) to [Spec, C], leaving a gap in the relative clause. When weak, it cannot license movement and as a result, the relative pronoun remains in situ and is pronounced as a resumptive pronoun. Second, it is assumed that $C$ is also endowed with a case feature and that only the element that has a matching case feature may undergo movement. The value of C's case feature is determined in terms of the active case: i.e., NOM in accusative languages and ABS in ergative languages (cf. Bobaljik 1993, Laka 1993). In Tongan, C's case feature is claimed to be [ABS] when its [+pron] feature is strong, and [ERG], when its [+pron] feature is weak. As a result, a resumptive pronoun is licensed only in a position associated with ERG. In short, the ergative pattern in question can be viewed as a consequence of morphological ergativity: the relativization rules refer to case.

Another phenomenon concerning syntactic ergativity involves a conjunction pea. Pea connects two clauses, the second of which may contain a gap, $e$, as illustrated in (2) below.

(2) $\mathrm{Na}^{\text {'e }}$ 'ita 'a Sione pea tangi $e$.

PST angry ABS Sione and cry

'Sione $\mathrm{i}_{\mathrm{i}}$ was angry and (he $\mathrm{e}_{\mathrm{i}}$ ) cried.'

The gap in the second clause and the coreferential argument in the first clause must bear the same case. Thus, combinations such as ABS-ERG and ERG-ABS are prohibited. See (3) below.

(3) a. ${ }^{*} \mathrm{Na}$ 'e poto 'a Sione pea fili 'a Pila.

PST smart ABS Sione and choose ABS Pila

'Sione was smart and (he) chose Pila.'

b. Na'e poto 'a Sione pea fili 'e Pila PST smart ABS Sione and choose ERG Pila 'Sione was smart and Pila chose (him).' 
(3a) is ungrammatical because coreference is intended between the ABS argument of the first clause and the ERG argument of the second clause.

Otsuka (2003) proposes that the gap in pea-constructions arises due to a PF deletion operation, which may apply only if the two items have identical sets of features. Given this requirement, an argument in the second clause can be deleted only if it has the same case as the coreferential argument; hence the ergative pattern. ${ }^{4}$ Again, syntactic ergativity can be viewed as a reflex of morphological ergativity: the gap must be licensed by case-feature matching.

\section{Properties of ' $o$-clauses}

' $O$-constructions demonstrate an ergative pattern different from that of peacoordination. Case matching is not a requirement. Rather, the relevant condition is that the antecedent must bear ABS. Combination such as ABS-ERG is permitted, whereas ERG-ERG is prohibited, as shown in (4) below.

(4) a. Na'e ha'u 'a Hina 'o taa'i $e_{i}$ 'a Mele. PST come ABS Hina and hit ABS Mele 'Hina came and hit Mele.'

b. Na'e fili 'e Sione $e_{i}$ 'a Mele 'o fiefia. PST choose ERG Sione ABS Mele and happy 'Sione chose Mele and (*he/she) was happy.'

c. *Na'e tamate' $\mathrm{i}$ 'e Lisiate $_{\mathrm{i}}$ 'a Tevita 'o ma'u $e_{\mathrm{i}}$ 'a e koloa. PST kill ERG Lisiate ABS Tevita and get ABS DEF treasure 'Lisiate killed Tevita and got the treasure.'

' $O$ is traditionally considered a conjunction along with pea and mo. Churchward (1953) observes the following semantic differences between these three items: pea is sequential ("and then"), mo is simultaneous ("and also"), and ' $o$ is consequential ("and so, as a result"). There is evidence to suggest that ' $o$ is a complementizer rather than a conjunction, however. First, note that unlike pea or $m o$, 'o cannot conjoin anything other than clauses. As shown in (5) below, nouns, adjectives, and adverbials can be conjoined by mo, and PPs, by pea. As demonstrated in both cases, the use of 'o results in ungrammaticality.

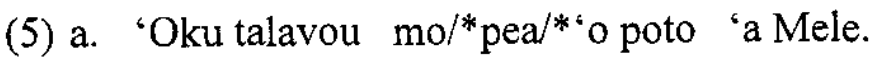
PRS beautiful and smart ABS Mele 'Mele is beautiful and smart.'

b. $\mathrm{Na}^{\text {'e }}$ 'alu 'a Sione $\mathrm{mo} /{ }^{*}$ pea/*'o Mele ki kolo. PST go ABS Sione and Mele to town 'Sione and Mele went to town.' 
c. Na'e 'alu 'a Sione ki Fisi pea/*mo/*`o ki Ha'amoa. PST go ABS Sione to Fiji and to Samoa 'Sione went to Fiji and then to Samoa.'

Second, while pea can be followed by a tensed full clause, the clause following ' $o$ cannot contain a tense marker.

(6) Na'e ha'u 'a Sione pea/*'o na'a ne fiefia. PST come ABS Sione and PST 3.s happy 'Sione came and he was happy.'

Note that overt subjects are permitted in ' $o$-clauses as long as no tense marker is present. See (7) below.

(7) Na'e ha'u 'a Sione 'o fiefia 'a Mele. PST come ABS Sione and happy ABS Mele

'Sione came and Mele was happy.'

In this respect, ' $o$-clauses are similar to subjunctive ke-clauses, which occur as sentential arguments or adjuncts. Ke-clauses are like English infinitival clauses (i.e., to-clauses) in their distribution and functions, except that they permit an overt, as well as null, subject. See (8) below.

(8) a. 'Oku sai ke (*'oku) 'alu ki ai 'a Sione. PRS good SUBJ PRS go to there ABS Sione 'It is good that Sione goes there.'

b. 'Oku ako lahi 'a Sione ke (*'oku) poto. PRS study much ABS Sione SUBJ PRS smart 'Sione studies to be smart.'

Finally, as noted earlier, 'o necessarily gives rise to a consequential interpretation. Sentences with ' $o$-clauses are most naturally translated as "so that ...". The tense interpretation of ' $o$-clauses can be best described as "unrealized" in the sense of Stowell (1982), who observes that this is a property of control infinitival clauses. Given that ' $O$-clauses are generally optional constituents, they are similar to infinitival adjuncts introduced by to-infinitives in English. Thus, I treat ' $O$ as a complementizer introducing a consequential adjunct, which adjoins to VP. ${ }^{5}$

\section{Null anaphor proSE}

In this section, we investigate the properties of the empty category that occurs in ' $O$-clauses and claim that the empty category in question cannot be either pro or PRO, but should be understood as a null anaphor, which I call prosE. 


\subsection{Empty categories in Tongan}

There are three kinds of empty categories in Tongan: PRO, pro, and $w h$-trace. ${ }^{6}$ An example of each is given in (9) below.

(9) a. 'Oku loto 'a Sione [ke ma'u PRO 'a e koloa] PRS want ABS Sione SUBJ get ABS DEF treasure 'Sione wants to get the treasure.'

b. 'Oku ma'u pro'a e koloa. PRS get ABS DEF treasure ' $(\mathrm{He})$ gets the treasure.'

c. Ko e hā na'e ma'u 'e Sione $t$ ? PRED DEF what PST get ERG Sione 'What did Sione get?'

Of these three, we have seen above that $w h$-traces are permissible only in positions associated with ABS. The null argument in ' $O$-clauses, on the other hand, may occur in ERG-marked positions (4a). Thus, we may safely assume that the null element in ' $O$-clauses is not a $w h$-trace.

The second possibility is pro. Note that what I call pro in Tongan is different from the null pronouns of the so-called pro-drop languages such as Spanish and Italian, which are licensed by rich agreement inflection on verbs. Rather, it is similar to the null arguments in Chinese and Japanese, which Huang $(1984,1989)$ treats as an instance of topic variable. Null arguments of this sort are typically context-dependent; their reference must have been established in the discourse. Accordingly, argument drop is impossible in an out-of-the-blue context. This is true of Tongan as well. Sentences with a null argument such as (9b) uttered out of context are infelicitous. In addition, pro in Tongan shows a unique property. It can only be third person singular. ${ }^{7}$ The use of pro as a first and/or second person pronoun results in ungrammaticality, even if the reference is clearly established in the discourse. Consider (10).

(10) $\mathrm{Na}^{\prime} \mathrm{aku}$ 'alu ki he fale kai. Na'e kai pro'a e ika. PST 1.s go to DEF house eat PST eat ABS DEF fish 'I went to the restaurant. (*I/he) ate fish.'

In contrast, the null argument in ' $o$-clauses can be coreferential with a first/second person argument; this is not expected of pro.

(11) $\mathrm{Na}$ 'a ku/ke 'alu'o mohe ai.

PST $1 . \mathrm{s} / 2 . \mathrm{s}$ go and sleep there

'I/you went and (I/you) slept there.'

Furthermore, recall that the antecedent of this empty argument must be in ABS. This can be also taken as evidence against the pro analysis, for if it were pro, it should be able to refer to any NP regardless of its Case. (12) below shows that pro in the embedded clause can refer to any argument in the matrix clause. 


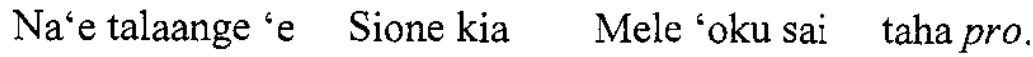 PST tell.DIR.3 ERG Sione to.PERS Mele PRS good one
'Sione told Mele (that) he/she is the best.'

Thus, we have reasons to believe that the empty category in 'o-clauses is not pro, but something else.

Let us now turn to PRO. PRO in Tongan deviates from the general description of PRO in several respects. First, PRO occurs in a position where an overt NP is also permitted. Compare (13) below with (9a).

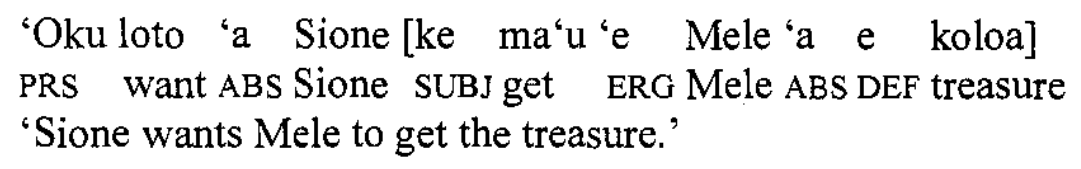

This is a peculiar property of $k e$-clauses, which is discussed extensively in Otsuka (2000). Ke-clauses permit both PRO and an overt NP in the subject position. The reason why the empty category in (9a) is regarded as PRO is that it cannot occur in the object position, as shown in (14).

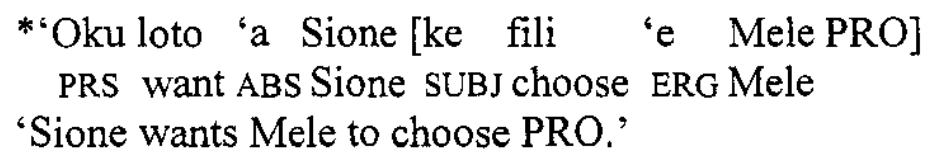

This fact distinguishes PRO from pro in Tongan, for nothing prohibits pro in the object position. In fact, (14) is grammatical if the empty category is taken to be pro, which in turn is taken to be coreferential with the discourse topic, but not the matrix subject.

$$
\begin{aligned}
& \text { 'Oku loto 'a Sione [ke fili 'e Mele pro] } \\
& \text { PRS want ABS Sione SUBJ choose ERG Mele } \\
& \text { 'Sione }{ }_{i} \text { wants that Mele choose him } *_{i j} \text {.' }
\end{aligned}
$$

There is another unique property of PRO in Tongan: PRO cannot occur as the subject of an intransitive verb. As shown in (16) below, when the embedded clause is intransitive, it must contain an overt pronoun if the embedded subject and the matrix subject are taken to be coreferential. On the other hand, if the embedded clause contains a null argument, it cannot be coreferential with the matrix subject. That is, control by the matrix subject is not possible. The only possible interpretation is the one where the empty category is taken to be pro, whose reference is determined by the discourse topic rather than the matrix argument. $^{8}$

\footnotetext{
a. 'Oku loto 'a Sione [ke*(ne) 'alu]. PRS want ABS Sione SUBJ 3.s go 'Sione wants to go.'
} 

b. 'Oku loto 'a Sione [ke 'alu pro]. PRS, want ABS Sione SUBJ go

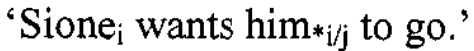

The null argument in ' $o$-clauses shows neither of these properties. First, it can occur in as a direct object, as shown in (17a). Second, it can also occur as the subject of an intransitive verb and be coreferential with the matrix argument. See $(17 \mathrm{~b})$.

a. Na'e ngāue lahi 'a Sione 'o fili 'e he pule $e$. PST work much ABS Sione and choose ERG DEF boss 'Sione worked hard so the boss should choose (him).'

b. Na'e tokoto 'a Sione 'o mālōlōe. PST lie.down ABS Sione and rest 'Sione lay down in order to rest.'

In summary, we have seen that the empty category in ' $O$-clauses is neither pro nor PRO.

\subsection{Null anaphor pro ${ }_{S E}$}

To recapitulate, the null argument in ' $o$-clauses has the following properties: a) unlike pro, it can be other than third person singular; b) unlike PRO, it can occur as $\mathrm{O}$; c) its antecedent must be in the matrix clause and ABS-marked; and d) it can be replaced by an overt pronoun. As for the last property, it has an interesting effect. As long as ' $o$-clauses contain an overt pronoun, the ergative constraint does not take effect: the pronoun can refer to the matrix argument that is marked as ERG.
a. Na'e fili 'e Sione 'a Mele'o e fiefia. PST choose ERG Sione ABS Mele and happy 'Sione chose Mele so *he/she should be happy.'
b. Na'e fili 'e Sione 'a Mele' 0 ne fiefia. PST choose ERG Sione ABS Mele and 3.s happy 'Sione chose Mele so he/she should be happy.'

This suggests that what is subject to the relevant constraint is not ' $o$-clauses per se, but rather the empty category in question.

I propose that the null argument in ' $O$-clauses is a null anaphor, whose feature specification is [tana(phor), -pronominal]. Its [+ana] feature makes it subject to binding principles, which require that this element be bound (in its binding domain). Hence, the null element in ' $O$-clauses must have an antecedent in the same sentence. Two facts need to be explained, however: a) its antecedent must be outside the ' $O$-clause; and b) its antecedent must be in ABS.

It should be noted that there are two kinds of anaphors: those that permit long-distance binding and those that do not. The former is known to exist in languages like Japanese, Chinese, and Icelandic. It is known that long-distance 
anaphors are of simplex form, and generally underspecified for phi-features if the language generally realizes phi-features morphologically. For example, in Japanese, the long distance anaphor zibun "self" contrasts with the local anaphor zibun-zisin "self-self"; in Dutch, the long distance anaphor is zich while the local anaphor is zichszelf. Following Reinhart and Reuland $(1991,1993)$ and Reuland and Reinhart (1995), I refer to the former as SE anaphors and the latter, SELF anaphors. It is SE anaphors that permit non-local binding. The empty category in ' $O$-clauses exhibits a property of non-local anaphors, suggesting that it is a kind of $\mathrm{SE}$ anaphor. For the sake of convenience, I call this element pro $_{\mathrm{SE}}$, a phonetically null reflexive pronoun of the SE-type. In the following section, we will discuss how binding relation is established in the phase based Minimalist framework (Chomsky 2000, 2001).

\section{Binding in the Minimalist Program}

Given that government is not regarded as a core syntactic relation in the Minimalist Program, the Binding Theory (Chomsky 1981) requires a drastic reinterpretation. Reuland (2001) proposes that binding, just like any other syntactic relations, should be understood as a consequence of basic operations such as Merge and Move. Below, I discuss how Reuland's approach can account for the properties of pro $_{\mathrm{SE}}$ in Tongan.

\subsection{Binding as a formal dependency}

Reuland (2001) claims that binding of SE-anaphors is a formal dependency which he calls CHAIN. This dependency is established between SE and its antecedent by virtue of movement of SE's formal features. Reuland's analysis is based on the following assumptions. First, whenever a checking configuration arises, checking must take place. Second, interpretable features can delete if such deletion would not violate the principle of recoverability of deletion. That is, if no information is lost due to deletion of the relevant features. Third, feature chains exist (contra Chomsky $(1995,2000))$.

Note that SE anaphor in Dutch (zich) is only partially specified for features: only for person (i.e., third person) and not for gender or number. Reuland (2001) argues that this property enables SE to form a CHAIN with its antecedent in the following fashion. First, SE's formal features $\left(\mathrm{FF}_{\mathrm{SE}}\right)$ adjoin to $\mathrm{V}$ in order to check its case feature. ${ }^{9}$ As $\mathrm{V}$ overtly raises to $\mathrm{T}$ in Dutch, $\mathrm{FF}_{\mathrm{SE}}$ raising yields a configuration in which $\mathrm{FF}_{\mathrm{SE}}$ is in a Spec-head relation with the NP in [Spec, T]. Note that prior to $\mathrm{FF}_{\mathrm{SE}}$ raising, V's phi-features were checked by the NP in its Spec and deleted, for they are uninterpretable. Meanwhile those on the NP would not delete, for they are interpretable. When SE adjoins to $V$ in $T$, this creates a checking configuration (i.e., Spec-head) between SE and the NP in [Spec, T]. Given that feature checking must apply whenever a checking configuration arises, SE's phi-features are automatically checked against those of the NP in [Spec, T]. This establishes a dependency between SE's phi-features and the NP in [Spec, T] in a way similar to the dependency established between the subject and $\mathrm{T}$. 
In Reuland's (2001) analysis, the difference between SE anaphors and pronominals lies in their feature composition. Recall that establishment of dependency is possible in this case because SE (i.e., zich) is only specified for person, which is an inherent feature and therefore, context independent. Hence, deletion of an occurrence of this feature under identity with another occurrence would not result in loss of any information that is necessary for interpretation. In contrast, such a dependency cannot be formed with a pronominal and the NP in [Spec, T], for pronominals (e.g., hem) are fully specified for features including number and gender. As number is an optional feature and is context dependent, deletion of an occurrence of such a feature is unrecoverable.

\subsection{Pro $_{S E}$ in Tongan}

In Reuland's model, binding relation is taken to be a formal dependency established by checking configuration between a head and XP in its Spec (specifically, the subject and $\mathrm{T}$ ). The bindee and its antecedent can enter into this relation by virtue of $\mathrm{FF}$ raising to $\mathrm{V}$. This $\mathrm{FF}$ movement is motivated by case reasons: the object NP must check its case. Two additional conditions must be met. First, V-raising to $T$ is overt and hence precedes FF raising to V. Second, FF of the NP in question must be only partially specified, consisting of only interpretable and inherent features such as person, as in the case of zich in Dutch.

The first condition is met in Tongan. V-raising is obligatory and overt, as evidenced by the $\mathrm{V}$-initial word order. The second condition is also met in Tongan; for the null anaphor can be bound by NPs of any number or person (gender is not a morphosyntactic category in Tongan). This situation is slightly different from zich, as it seems that pro $o_{\mathrm{SE}}$ is not specified at all for phi-features. We may postulate that pro $_{\mathrm{SE}}$ has a categorical feature $[+\mathrm{D}]$, unspecified phifeatures [person, number], and a case feature. Given the requirement of Full Interpretation (FI), these features must be checked. As far as phi-features are concerned, they must be assigned some values. Binding, then, can be understood as phi-feature value assignment in this case. It is motivated by the FI, and is achieved by feature checking. Feature checking is achieved by feature match, which should be understood as feature-type match rather than feature-value match (cf. Chomsky 2000). Prose's phi-features are checked by matching features of the same type, i.e., phi-features of its antecedent. Through this checking process, the two sets of phi-features are identified, with those of pro $o_{S E}$ deleted as a result, establishing a formal dependency between the two elements.

Adopting Reuland's (2001) model, I propose the following analysis of pro $_{\mathrm{SE}}$ in Tongan. FF of pro $o_{\mathrm{SE}}$ raises to attach to $v$ of the matrix clause and enter into a checking configuration with the NP in [Spec, v], whereby a formal dependency (i.e., binding) is established between the two. There are, however, some issues that must be addressed regarding how the proposed $\mathrm{FF}$ raising is motivated and achieved in Tongan. Note that Tongan differs from Dutch in two respects. First, case marking in Tongan is ergative, which presumably involves a mechanism quite different from that of an accusative system. Second, unlike zich in Dutch, only non-local binding is possible for pro ${ }_{\mathrm{SE}}$ in Tongan: its antecedent 
must be outside ' $o$-clauses and, as we will see later, it cannot occur in simple sentences.

In the current study, ABS and ERG are both taken to be structural; the former is checked by $v$ and the latter, by $\mathrm{T}$ (Otsuka 2000, 2002, 2003). The difference between ergative and accusative systems is essentially the choice of "active" functional head, $\mathrm{T}$ in accusative languages and $v$ in ergative languages (cf. Levin and Massam 1984, Bobaljik 1993, Laka 1993). The "active" functional head is the one always available for case checking. In accusative languages, $T$ is always available and has a case feature [NOM], whereas $v$ is only present in transitive constructions. In contrast, in ergative languages, $v$ with [ABS] is present in intransitive constructions as well as transitive, while $\mathrm{T}$ may or may not be endowed with a case feature [ERG] (Otsuka 2003). When $T$ is not endowed with a case feature, only intransitive constructions can survive the derivation. The derivation would crash if the verb is transitive, for the subject NP would never be able to have its case feature checked.

Let us consider how prosE's case is checked. Given that overt NPs, both ABS and ERG, can occur in ' $O$-clauses, we may assume that both ABS and ERG are available in ' $O$-clauses. That is, pro $o_{\mathrm{SE}}$ can and therefore, must have its case checked inside ' $o$-clauses. If case is the motivation for FF-raising that is necessary to establish a binding relation, pro ${ }_{\mathrm{SE}}$ does not have any reason to move its $\mathrm{FF}$ to any higher position, for the relevant feature has already been checked. Thus, the trigger for FF-movement must be some feature(s) other than case. I propose that it is phi-features that motivate FF-movement.

\subsection{Analysis}

The gist of the current proposal is that pro ${ }_{\mathrm{SE}}$ and its antecedent establish a formal dependency through feature checking. This dependency is established by FF raising of pro ${ }_{\mathrm{SE}}$ 's phi-features to the matrix $v$. In order for such movement to be licensed, however, the following conditions must be met. First, prosE's phifeatures must not delete even after its case feature has been checked. This is problematic given Chomsky's (2000) approach, in which a) case is considered to be a by-product of phi-feature checking and b) an NP becomes inactive to computation once its case is checked. Second, the matrix $v$ 's phi-features must also remain accessible so that Agree can apply to $v$ and prose. This raises a question, considering that $v$ 's phi-features are uninterpretable, which are generally assumed to obligatorily delete upon checking (Chomsky 1995, 2000). Thus, the current analysis requires two additional stipulations in order to meet these two conditions.

(19) a. An NP remains active as long as it has some uninterpretable feature.

Features with unspecified values are uninterpretable.

b. Uninterpretable features on an active functional head remain accessible until the relevant phase is completed.

Let us consider the derivation in question step by step. First, Agree applies to pro $_{\mathrm{SE}}$ and the relevant functional head $(v$ or T) inside the embedded ' $o$-clause. 
Recall that Agree holds in terms of feature types rather than feature values. In this case, the relevant feature type is phi-features. As a result of this operation, pro $o_{\mathrm{SE}}$ 's case feature is checked and assigned a specific value (ABS or ERG). Note, however, that its phi-features fail to receive any specific values, for $v$ 's phifeatures are uninterpretable. Thus, prose still has features whose values are unspecified, whence the FI cannot be satisfied. Given (19a), prosE remains active although its case feature has been successfully checked.

The next step builds a new phase, $v \mathrm{P}$ on top of the 'o-clause. As mentioned above, ' $o$-clauses are taken to be adjoined to VP to its left. ${ }^{10}$ In this phase, the following operations take place. First, Agree applies to the phi-features of the matrix $v$ and those of NP inside the $v \mathrm{P}$ (subject if $\mathrm{V}$ is intransitive, object if $\mathrm{V}$ is transitive). As a result of this operation, phi-features on $v$ and on the NP are checked, and the NP's case feature is assigned a specific value, [ABS]. Due to (19b), however, $v$ 's phi-features still remain accessible to subsequent operations within the phase. Thus, Agree applies to $v$ and pro $_{\mathrm{SE}}$. By virtue of this operation, pro $_{\mathrm{SE}}$ forms a dependency with the ABS-NP compositionally; there is a dependency between pro $_{\mathrm{SE}}$ and $v$, which in turn forms a dependency with the NP through the previous application of Agree. Pro ${ }_{\mathrm{SE}}$ 's phi-features identified with those of the NP and the operation forms a CHAIN $<\mathrm{NP}$, pro $\mathrm{SE}>$. As a consequence, pro $_{\mathrm{SE}}$ is interpreted as coreferential with the ABS-NP in the matrix clause. $^{11}$

\section{Discussion: Long-distance anaphors and case}

The current analysis explains how the null argument in ' $O$-clauses is interpreted as coreferential with the ABS-marked NP of the matrix clause. It also correctly predicts that coreference between pro $o_{\mathrm{SE}}$ and the ERG-marked NP is impossible. Note that in the present approach, in order to establish a formal dependency with the ERG-marked NP, prosE's phi-features must adjoin to T instead of $v$. However, such movement is impossible for two reasons. First, note that $T$ is not the active functional head in Tongan. Thus, T's phi-features become automatically inaccessible once they are checked against the subject NP (i.e., the ERG-marked

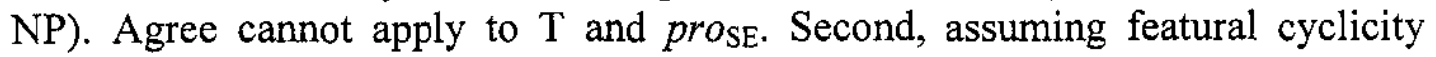
(Chomsky 1995), feature checking must take place at a first opportunity. Furthermore, given the Phase Impenetrability Constraint (Chomsky 2000), feature checking cannot take place across a phase boundary. In other words, pro $o_{\mathrm{SE}}$ must check its phi-features when the first opportunity arises, namely, within the matrix $\nu \mathrm{P}$. Note that $\mathrm{T}$ is outside the relevant phase. Thus, pro ${ }_{\mathrm{SE}}$ does not have access to $\mathrm{T}$ unless it moves up to the next phase (i.e., CP). Yet, it cannot do so, since $v$ provides an opportunity for feature checking.

The same argument can be used to account for the fact that pro $o_{\mathrm{SE}}$ cannot occur in a simple sentence, as shown in (20) below.

$$
\begin{aligned}
& \text { *Na'e fili 'e Sione } \text { pro }_{\mathrm{SEi}} \\
& \mathrm{PST} \text { choose ERG Sione } \\
& \text { Intended meaning: 'Sione chose himself.' }
\end{aligned}
$$


In order to obtain the reflexive reading, the ERG-marked NP Sione and pro SE $_{\text {S }}$ must form a CHAIN. However, such a CHAIN cannot be formed. Recall that $\mathrm{T}$ is not the active functional head in this language. Hence, once Agree has applied to $\mathrm{T}$ and the subject, $\mathrm{T}$ 's uninterpretable features delete and become inaccessible to computation.

Finally, it should also be noted that the analysis proposed here has some intriguing implication for other instances of long-distance anaphors. It is well-known that non-local binding of SE anaphors is subject-oriented. Longdistance binding by a non-subject (e.g., direct object) is not possible, as illustrated by the Japanese example in (21) below.

$$
\begin{aligned}
& \text { John }_{\mathrm{i}} \text {-ga Bill } \text {-ni }_{\text {-neter }} \text {-ga } \text { zibun }_{\mathrm{i} / *_{\mathrm{j} / \mathrm{k}} \text {-O }} \text { kaita to] itta. } \\
& \text { John-NOM Bill -DAT Peter- NOM SE -ACC painted that said } \\
& \text { 'John } n_{\mathrm{i}} \text { told Bill } \mathrm{j}_{\mathrm{j}} \text { that } \text { Peter }_{\mathrm{k}} \text { painted } \text { self }_{\mathrm{i} /{ }_{\mathrm{j}} / \mathrm{k}} \text {.' }
\end{aligned}
$$

In the current approach, this property of long distance anaphors can be readily accounted for. Recall that the active functional head is $\mathrm{T}$ in accusative languages. Thus, the condition (19) applies to $\mathrm{T}$ rather than $v$. In other words, whatever uninterpretable features $v$ has, they must delete once checked. Consequently, $v$ 's phi-features are never available for pro $_{\mathrm{SE}}$. As pro $o_{\mathrm{SE}}$ cannot check its phi-features (i.e., have their values specified) inside $v \mathrm{P}$, it moves up to the next phase. On the other hand, T's phi-features remain accessible due to the condition (19a) and therefore, $T$ can establish the required dependency with prose. In accusative languages, the NP that forms a dependency with $\mathrm{T}$ is the one bearing NOM, i.e., the subject.

\section{Conclusion}

I have argued that the ergative pattern concerning ' $O$-constructions in Tongan can also viewed as a result of morphological ergativity, i.e., the fact that the active functional head is $v$. In the current analysis, the null argument in ' $O$-clauses is taken to be a phonetically null SE anaphor. Its interpretation relies on binding, a dependency established due to phi-feature matching. I have argued that the proposed phi-feature matching is possible only with the active functional head. Thus, in Tongan, it can be coreferential only with ABS-arguments. In contrast; in accusative languages its antecedent must bear NOM, the active case in the system. This is supported by the fact that long-distance anaphors in languages like Japanese and Chinese are subject-oriented. To conclude, the current study lends further support to Otsuka's $(2002,2003)$ position that syntactic ergativity should be understood as a reflex of morphological ergativity. 


\section{Endnotes}

ACKNOWLEDGEMENT: Many thanks to the audience at AFLA 11 and the organizers of the conference. I am particularly thankful to Edith Aldridge, William O'Grady, Eric Potsdam, and Lisa Travis for helpful comments. Special thanks to Lose Kaufusi and Havila Saafi for their invaluable help with the Tongan data.

1. Bittner and Hale (1996a, b) propose that syntactic ergativity arises when ABSNPs are structurally higher than ERG-NPs and that the structural position of ABS is determined by a parameter concerning VP's transparency to government. In their system, it is assumed that $\mathrm{C}$ assigns ABS under government. If VPs are opaque to government, ABS-NPs must move to [Spec, IP] in order to receive case and end up higher than ERG-NPs.

2. The subject pronouns are clitic and therefore occur immediately after the tense marker, while the default word order in Tongan is VSO. Also note that the past tense marker $n a^{\prime} a$ has an allomorph $n a^{\prime} e$, which is used when followed by a clitic pronoun.

3. Abbreviations used in this paper are as follows: $\mathrm{ABS}=$ absolutive, $\mathrm{ACC}=$ accusative, $\mathrm{DAT}=$ dative, $\mathrm{DEF}=$ definite, $\mathrm{DIR}=$ directional, $\mathrm{ERG}=$ ergative, $\mathrm{NOM}=$ nominative, $\mathrm{PERS}=$ personal, $\mathrm{PRED}=$ predicate, $\mathrm{PRS}=$ present, $\mathrm{PST}=$ past, $\mathrm{S}=$ singular, SUBJ $=$ subjunctive, $1=$ first person, $2=$ second person, $3=$ third person. 4. This deviates from Chomsky's $(1995,2000)$ claim that case features are deleted once checked. I argue that case features on NPs remain accessible after checking in the sense that their value is accessible to the computation, as I have proposed elsewhere on an independent ground concerning the distribution of resumptive pronouns (Otsuka 2002).

5. Chung (1978) also treats ' $o$ as a complementizer, but in a slightly different way. For her, ' $o$ is a morphological consequence of raising, replacing the subjunctive particle $k e$, similar to the alternation between that and to in English. Thus, ' $O$-clauses are considered to be complements rather than adjuncts. The phenomenon Chung refers to as "raising" is illustrated in (i) below.

(i) a. 'oku lava ke ha'u 'a Sione.

PRS able SUBJ come ABS Sione

'Sione can come.'

b. 'oku lava'a Sione 'o ha'u.

PRS able ABS Sione and come

'Sione can come.'

I argue, however, that there is no derivational relation between (ia) and (ib), i.e., (ib) is not an instance of raising. Lava ' $o$ is one of the two instances of idiomatic usage of ' $o$. See Otsuka (2000) for discussion.

6. I have not found any evidence for NP-traces in Tongan. For one thing, passive does not exist in Tongan. Furthermore, predicates equivalent to seem and likely do not permit raising, but only occur with the expletive subject. See Otsuka (2000) for details. 
7. This is true if the empty argument is used as a personal pronoun referring to a [+human] item. It should be noted that [-human] objects are always realized as a null pronoun even if they are [+plural].

8. This condition can be viewed as prohibition of PRO in ABS-marked positions. One could consider is a kind of syntactic ergativity in that the distribution of PRO distinguishes ABS from ERG, preferring the latter. Intriguing as it is, I will not discuss this phenomenon further in this paper for the interest of space.

9. Note that Reuland's (2001) analysis is based on Chomsky (1995), in which Case and phi-features are considered to be independent formal features.

10. Contra Kayne (1997), who claims that only left adjunction, is permitted in UG.

11. As Edith Aldridge points out, the proposed operation involves extraction out of adjuncts, which is generally taken to be illicit in UG. While acknowledging this as a potential problem, I would like to suggest a couple of possible solutions, albeit somewhat speculative. First, note that the long-standing assumption that extraction out of adjuncts is prohibited has been challenged elsewhere. Hornstein (1999), for example, permits such movement in his analysis of control into adjuncts. (Thanks to Eric Potsdam for bringing this point to my attention.) Alternatively, we may postulate that consequential ' $o$-clauses are complements in a way similar to Nilsen's (2000) analysis of circumstantial adverbials as complements. I hope to return to this issue in future work.

\section{References}

Bittner, Maria, and Ken Hale. 1996a. The structural determination of Case and agreement. Linguistic Inquiry 27: 1-68.

Bittner, Maria, and Ken Hale. 1996b. Ergativity: Toward a theory of a heterogeneous class. Linguistic Inquiry 27: 531-604.

Bobaljik, Jonathan. 1993. On ergativity and ergative unergatives. Papers on Case and agreement II, MIT Working Papers in Linguistics 19, ed. by Colin Philips, 45-88.

Chomsky, Noam. 1995. The Minimalist Program. Cambridge, MA: MIT Press.

Chomsky, Noam. 2000. Minimalist inquiry: The framework. Step by Step: Essays on Minimalist Syntax in Honor of Howard Lasnik, ed. by Roger Martin, David Michaels, and Juan Uriagereka, 89-155. Cambridge, Mass.: MIT Press.

Chomsky, Noam 2001. Derivation by phase. Ken Hale: A life in language, ed. by Michael Kenstowicz, 1-52. Cambridge, Mass.: MIT Press.

Chung, Sandra. 1978. Case marking and grammatical relations in Polynesian. Austin: University of Texas Press.

Churchward, C. M. 1953. Tongan Grammar. Oxford: Oxford U. Press.

Dixon, R.M.W. 1979. Ergativity. Language 55: 59-138.

Dixon, R.M.W. 1994. Ergativity. Cambridge: Cambridge University Press.

Hornstein, Norbert. Movement and control. Linguistic Inquiry 30: 69-96. 
Huang, C. T. James. (1984) On the distribution and reference of empty pronouns, Linguistic Inquiry 15: 531-574.

Huang, C. T. James. (1989) Pro-drop in Chinese: A generalized control theory. The Null Subject Parameter, ed. by Osvaldo Jaeggli and Kenneth J. Safir, 185-214. Dordrecht: Kluwer Academic.

Kayne, Richard. 1994. Antisymmetry. Cambridge, Mass.: MIT Press.

Laka, Itziar. 1993. Unergatives that assigns ergative, unaccusatives that assign accusative. Papers on Case and agreement I. MIT Working Papers in Linguistics 18, ed. by Jonathan Bobaljik and Colin Philips, 149-172.

Levin, Juliette, and Diane Massam. 1984. Surface ergativity" Case-/theta relations re-examined. Proceedings of NELS 15, 286-301. GLSA, University of Massachusetts.

Massam, Diane. 2000. VSO and VOS: Aspects of Niuean word order. The syntax of verb initial languages, ed. by Andrew Carnie and Eithne Guilfoyle, 97116. Oxford: Oxford University Press.

Massam, Diane. 2001. Pseudo noun incorporation in Niuean. Natural Language and Linguistic Theory 19: 153-197.

Nilsen, Øystein. 2000. The syntax of circumstantial adverbials. Oslo: Norvus Press.

Otsuka, Yuko. 2000. Ergativity in Tongan. Doctoral dissertation. University of Oxford.

Otsuka, Yuko. 2002. Syntactic ergativity in Tongan: Resumptive pronouns revisited. Ms. University of Hawai' $i$.

Otsuka, Yuko. 2003. Two Derivations of VSO: A Comparative Study of Niuean and Tongan. Ms. University of Hawai' $i$.

Reinhart, Tanya, and Eric Reuland. 1991. Anaphors and logophors: An argument structure perspective. Long-distance anaphora, ed. by Jan Koster and Eric Reuland, 283-321. Cambridge: Cambridge University Press.

Reinhart, Tanya, and Eric Reuland. 1993. Reflexivity. Linguistic Inquiry 24: 657720.

Reuland, Eric. 2001. Primitives of binding. Linguistic Inquiry 13: 561-570

Reuland, Eric, and Tanya Reinhart. 1995. Pronouns, anaphors and Case. Studies in comparative Germanic syntax, ed. by Hubert Haider, Susan Olsen, and Sten Vikner, 241-269. Dordrecht: Kluwer.

Stowell, Tim. 1982. The tense of infinitives. Linguistic Inquiry 13: 561-570.

Suñer, Margarita. 1998. Resumptive restrictive relatives: A crosslinguistic perspective. Language 74: 335-364.

\author{
Yuko Otsuka \\ University of Hawai'i at Mānoa \\ Department of Linguistics \\ 1890 East-West Road, Honolulu, HI96822 \\ USA \\ yotsuka@hawaii.edu
}

